\title{
Influence of interface structure on mass transport in phase boundaries between different ionic materials
}

\author{
Experimental studies and formal considerations
}

\author{
Carsten Korte $\cdot$ N. Schichtel $\cdot$ D. Hesse $\cdot$ \\ J. Janek
}

Received: 10 November 2008/ Accepted: 20 December 2008/Published online: 27 March 2009

(c) Springer-Verlag 2009

\begin{abstract}
Internal and external interfaces in solids exhibit completely different transport properties compared to the bulk. Transport parallel to grain or phase boundaries is usually strongly enhanced. Transport perpendicular to an interface is usually blocked, i.e., transport across an interface is often much slower. Due to the high density of interfaces in modern micro- and nanoscaled devices, a severe influence on the total transport properties can be expected. In contrast to diffusion in metal grain boundaries, transport phenomena in boundaries of ionic materials are still less understood. The specific transport properties along metal grain boundaries are explained by structural factors like packing densities or dislocation densities in the interface region. In most studies dealing with ionic materials, the interfacial transport properties are merely explained by the influence of space charge regions. In this study the influence of the interface structure on the interfacial transport properties of ionic materials is discussed in analogy to metallic materials. A qualitative model based on the density of misfit dislocations and on interfacial strain is introduced for (untilted and untwisted) phase boundaries. For experimental verification, the interfacial ionic conductivity of different multilayer systems consisting of stabilised $\mathrm{ZrO}_{2}$ and an insulating oxide is investigated as a funtion of structural mismatch. As predicted by the model, the interfacial conductivity increases when the lattice mismatch is increased.
\end{abstract}

C. Korte $(\square) \cdot$ N. Schichtel $\cdot$ J. Janek

Physikalisch-Chemisches Institut, Justus-Liebig-Universität

Gießen, Giessen, Germany

e-mail: carsten.korte@phys.chemie.uni-giessen.de

D. Hesse

Max-Planck-Institut für Mikrostrukturphysik, Halle (Saale), Germany
Keywords Interface structure - Ionic conductivity · Nanoionics $\cdot$ Multilayers $\cdot$ Pulsed laser deposition

\section{Introduction}

In many technical applications, functional ceramics are employed. They are processed as thin films, multilayers or multiphase composites. Ionic and non-metallic compounds like (transition) metal oxides and nitrides, silicon dioxide and silicates are used in integrated circuits as insulating and dielectric layers in miniaturised capacitors and metal-oxide field effect transistors (MOSFET) [1, 2]. Structured ferroelectric layers are discussed as a possible functional material for permanent memory devices (FeRAM) [3, 4]. Piezoelectric materials are used in mechanic actuators. Ceramic thin films are also part of many chemical and physical sensor systems, like gas sensors made from semiconducting oxides or GMR, TMR and SQUID magnetic field sensors [5, 6]. In solid oxide fuel cells (SOFC) mixed ionic and electronic conducting thin films are used as cathodes [7, 8].

Due to ongoing miniaturisation in many of these applications, the influence of inner and outer interfaces on the total properties of the system is increasing. Interfaces of a solid may exhibit a completely different microscopic structure and different thermodynamic and kinetic properties compared to the bulk. In many experimental investigations it has been shown that the mass and charge transport parallel to an interface is highly enhanced. In contrast to this observation, transport across an interface is usually hindered. Grain and phase boundaries usually act as fast transport paths along and as barriers across the interface plane.

Unlike transport in the volume, mass and charge transport in ionic materials along interfaces and its dependence 
on the interfacial structure are less understood. Most of the experimental [9-30] and theoretical studies [31-38] of ionic materials that can be found in the literature interpret the special properties of grain and phase boundaries for transport by the formation of space charge regions. In a space charge region, a depletion or accumulation of mobile defects occurs, causing a local variation of the transport properties close to the interface. A constant mobility is typically assumed. Especially the treatments by Maier et al. [36, 37] and Jiang et al. [32] have to be noted.

Due to the high density of mobile charge carriers, space charge regions do not exist in metallic systems. The transport properties of grain boundaries in metals are usually attributed to a local interface structure, which differs significantly from the bulk. Important influencing factors are the local packing density (density of reciprocal lattice sites, $\Sigma$-value) for large angle boundaries and the dislocation density (depending on the tilt angle) for small angle boundaries. Compared to ionic systems much more experimental [39-46] and theoretical studies [35, 47-50] can be found for grain boundary transport in metals and alloys. Only a selection of references for interfacial transport in ionic materials and metals can be given.

The question whether there is also an influence of the interface structure on the interfacial transport properties in ionic materials is only scarcely documented in the literature, notwithstanding the extensive investigation of metal grain boundaries. More specifically, there is no theoretical treatment of the qualitative and quantitative influence of interface structure on the interfacial transport properties reported. In this paper we would like to highlight this point by introducing a qualitative model based on the density of misfit dislocations and the interfacial strain. Own experimental investigations on the ionic conductivity of multilayered thinfilm systems and experimental studies found in the literature will be compared with the predictions of the model.

\section{Structural effects of the interfacial ionic conductivity}

In a region close to a phase or a grain boundary between two crystallites, the intensive thermodynamic parameters like defect and component concentrations, chemical and electric potentials undergo an abrupt change. In this region large chemical and electrical potential gradients appear. Different lattice structures may also cause large elastic strains in the interface region. The physical and chemical properties of interfaces and interfacial regions differ significantly from the bulk. As mentioned above, the enhanced transport properties along interfaces and the blocked transport across interfaces are explained in many experimental and formal articles by space charge effects. Space charge models cannot be applied to extrinsic systems with a high concentration of mobile charge carriers. The extent of the space charge regions becomes very small.

To estimate the possible influence of the interface structure on the ionic transport along the interface, we consider a simplified boundary between two different phases 1 and 2 as a model [19]. The phase boundary is situated between two crystallites with the same or closely related lattice symmetries. There is no tilt or twist between the low indexed lattice planes in both crystallites forming the boundary. With varying lattice mismatch $f_{12}$ between the close-packed lattice planes, the interface structure changes from coherent to semicoherent with increasing density of misfit dislocations.

$f_{12}=\frac{d_{h k l, 2}-d_{h k l, 1}}{d_{h k l, 1}}$

Here, $d_{h k l, 1}$ and $d_{h k l, 2}$ are the lattice spacings between the close-packed planes perpendicular to the interface. In case of an interface between two crystallites with different symmetry and high lattice mismatch, an incoherent interface is formed.

For a coherent interface the range of the stress fields into the adjacent crystallites depends on their geometry. In case that the extent of the boundary is large compared to the thickness (or to the height) of a crystallite, it will be elastically strained almost as a whole (e.g., large extended crystallites in a thin film). In case the extent of the boundary is small compared to the thickness of the crystallite, only a region close to the boundary will be strongly strained, as a relaxation of the strain can take place by deformation of the grains (e.g., columnar crystallites in thin films [51-53]).

In the following, we assume that phase 1 is the ionic conductor and phase 2 the insulator. For small lattice misfits, there is only elastic strain $\varepsilon_{12}$, which can influence the transport properties of the ionic conductor. The ionic conductivity of a distinct ionic species is the sum of the partial conductivities of the mobile lattice defects that cause the charge transport. In the case of Frenkel type oxygen-ion conductors, one has to consider oxygen vacancies $\mathrm{V}_{\mathrm{O}}^{.}$and oxygen interstitials $\mathrm{O}_{i}^{\prime \prime}$ for the oxygenion conductivity $\sigma_{\mathrm{O}^{2-}}$ :

$\sigma_{\mathrm{O}^{2-}}=\sigma_{\mathrm{V}}+\sigma_{\mathrm{I}}$

In the following, the index "V" is used for oxygen vacancies and the index "I" for oxygen interstitials. The partial conductivity $\sigma_{i}$ of each mobile defect $i$ depends on its free migration enthalpy $\Delta G_{i}^{\mathrm{M}}$ and on its concentration $c_{i}$ $(i=\mathrm{I}, \mathrm{V})$ :

$\sigma_{i}=\frac{\left(z_{i} F\right)^{2}}{R T} c_{i} \beta d_{i}^{2} \omega_{0, i} \exp \left(-\frac{\Delta G_{i}^{\mathrm{M}}}{R T}\right)$

The jump distance of the defect $i$ is denoted with $d_{i}$ and its charge number with $z_{i}$. In case of vacancy transport, the 
prefactor $\omega_{0, i}$ depends on the vibration frequency of the regular lattice atoms. In case of interstitial transport, it depends on the vibration frequency of the defect itself. $\beta_{i}$ is the geometry factor for the movement of the defect. For primitive cubic structures, the geometry factor is equal to $1 / 6$.

When considering Eqs. 2 and 3 as well as the prevailing defect equilibrium ${ }^{1}$ one gets the following expression for the oxygen-ion conduction of an (undoped, intrinsic) oxygen-ion conductor:

$$
\begin{aligned}
& \sigma_{\mathrm{O}^{2-}}=\frac{(2 F)^{2}}{R T} \frac{1}{V_{\mathrm{m}}} \exp \left(-\frac{\Delta G_{\mathrm{O}^{2-}}^{\mathrm{F}, 0}}{2 R T}\right) \times \\
& {\left[\beta_{\mathrm{I}} d_{\mathrm{I}}^{2} \omega_{0, \mathrm{I}} \exp \left(-\frac{\Delta G_{\mathrm{I}}^{\mathrm{M}}}{R T}\right)+\beta_{\mathrm{V}} d_{\mathrm{V}}^{2} \omega_{0, \mathrm{~V}} \exp \left(-\frac{\Delta G_{\mathrm{V}}^{\mathrm{M}}}{R T}\right)\right]}
\end{aligned}
$$

Here, $\Delta G_{\mathrm{O}^{2-}}^{\mathrm{F}, 0}$ is the free (Frenkel) defect formation enthalpy and $V_{\mathrm{m}}$ the molar volume of the ionic conductor. In intrinsic systems, the mobility of one defect usually exceeds the mobility of the other defect; thus, the corresponding exponential term in the squared brackets can be neglected. For highly doped (extrinsic) materials, the concentration of one mobile defect exceeds all other defect concentrations. For oxygen-ion conductors like YSZ, CSZ or CGO, one gets according to Eqs. 2 and 3:

$\sigma_{\mathrm{O}^{2-}}=\frac{(2 F)^{2}}{R T} c_{\mathrm{V}}^{\text {ext }} \beta_{\mathrm{V}} d_{\mathrm{V}}^{2} \omega_{0, \mathrm{~V}} \exp \left(-\frac{\Delta G_{\mathrm{V}}^{\mathrm{M}}}{R T}\right)$

The extrinsically fixed oxygen vacancy concentration $c_{\mathrm{V}}^{\mathrm{ext}}$ as well as all other temperature-independent parameters can be merged in a single preexponential factor $\sigma_{\mathrm{O}^{2-}}^{0}$ to obtain an Arrhenius-like expression:

$\sigma_{\mathrm{O}^{2-}}=\frac{\sigma_{\mathrm{O}^{2-}}^{0}}{T} \exp \left(-\frac{\Delta H_{\mathrm{V}}^{\mathrm{M}}}{R T}\right)$

$\Delta H_{\mathrm{V}}^{\mathrm{M}}$ denotes the migration enthalpy. In solids it is nearly identical with the activation enthalpy $E_{\mathrm{a}, \mathrm{V}}$.

The free migration enthalpies and the free (Frenkel) defect formation enthalpy and thus the transport parameters like $\sigma_{\mathrm{O}^{2-}}$ are pressure dependent ${ }^{2}$. For an extrinsic oxygen conductor one gets by differentiating Eq. 5 with respect to the pressure $p$ :

$$
\left(\frac{\partial \ln \sigma_{\mathrm{O}^{2-}}}{\partial p}\right)_{T} \approx-\frac{\Delta V_{\mathrm{V}}^{\mathrm{M}}}{R T}
$$

For a vacancy-type jump mechanism, the migration volume $\Delta V_{\mathrm{V}}^{\mathrm{M}}$ is usually positive, i.e., the lattice is locally expanded when the jumping ion reaches its transition state. In Eq. 7 it is assumed that the pressure dependence of the prefactor $\omega_{0, \mathrm{~V}}$, i.e., the vibration frequency of the regular lattice atoms, as

\footnotetext{
${ }^{1}$ Frenkel equilibrium: $c_{\mathrm{I}} c_{\mathrm{V}}=\frac{1}{V_{\mathrm{m}}^{2}} \exp \left(-\frac{\Delta G_{O^{2-}}^{\mathrm{F}, 0}}{R T}\right)$

2 It is given: $\left(\frac{\partial \Delta G_{\mathrm{V}}^{\mathrm{M}}}{\partial p}\right)_{T}=\Delta V_{\mathrm{V}}^{\mathrm{M}}$
}

well as the pressure dependence of the jump distance $d_{\mathrm{V}}$, is negligible compared to the exponential term.

The corresponding (isostatic) pressure $p$ in phase 1 (ionic conductor) close to a coherent phase boundary caused by the biaxial elastic strain $\varepsilon_{12}$ in the interface yields $^{3}$ :

$p=-\frac{2}{3} \frac{Y_{1}}{1-v_{1}} \varepsilon_{12}$

Here, $Y_{1}$ is the elasticity module and $v_{1}$ the Poisson ratio of phase 1. In a coherent interface the lattice misfit $f_{12}$ is completely compensated by the elastic strains in both adjacent crystallites, $\varepsilon_{12}$ and $\varepsilon_{21}$. Thus, using Eq. 8, the isostatic pressure $p$ close to the interface is proportional to the lattice misfit $f_{12}$. According to Eq. 7 one gets an exponential dependence of the ionic conductivity $\sigma_{\mathrm{O}^{2-} \text {,int }}$ in the ionic conductor close to the interface on the migration volume $\Delta V_{\mathrm{V}}^{\mathrm{M}}$ of vacancies and on the lattice misfit:

$\ln \frac{\sigma_{\mathrm{O}^{2-}, \text { int }}}{\sigma_{\mathrm{O}^{2-}, \text { vol }}} \sim \Delta V_{\mathrm{V}}^{\mathrm{M}} f_{12}$

$\sigma_{\mathrm{O}^{2-} \text {,int }} / \sigma_{\mathrm{O}^{2-} \text {,vol }}$ is the ratio between the conductivity of the interface region and the bulk conductivity. For a vacancy type jump mechanism $\left(\Delta V_{\mathrm{V}}^{\mathrm{M}}>0\right)$ we should expect an increase of the interface conductivity in case of dilatative strain $f_{12}>0$ (negative pressure). In case of compressive strain $f_{12}<0$ the interface conductivity $\sigma_{\mathrm{O}^{2-} \text {,int }}$ should be decreased compared to the bulk.

In contrast to the free migration enthalpy $\Delta G_{\mathrm{V}}^{\mathrm{M}}$, the migration enthalpy $\Delta H_{\mathrm{V}}^{\mathrm{M}}$ is readily accessible from temperature-dependent measurements of the conductivity or the diffusion coefficient. The migration enthalpy $\Delta H_{\mathrm{V}}^{\mathrm{M}}$ in Eq. 6, respectively the activation energy $E_{\mathrm{a}}, \mathrm{V}$, is also pressure dependent and is influenced by the biaxial strain in a region close to the phase boundary.

The pressure dependence $\left(\partial \Delta H_{\mathrm{V}}^{\mathrm{M}} / \partial p\right)_{T}$ of the migration enthalpy and thus also the pressure dependence $\left(\partial E_{\mathrm{a}, \mathrm{V}} / \partial p\right)_{T}$ of the activation energy can be derived from the pressure dependence $\left(\partial \Delta G_{\mathrm{V}}^{\mathrm{M}} / \partial p\right)_{T}$ of the free migration enthalpy ${ }^{4}$ :

3 The isostatic pressure $p$ is given for the stress components $\sigma_{x x}$ and $\sigma_{y y}$ parallel and $\sigma_{z z}$ perpendicular to the interface plane:

$p=-\frac{1}{3}\left(\sigma_{x x}+\sigma_{y y}+\sigma_{z z}\right)$

In the case of biaxial strain in a thin film, $\varepsilon_{x x}=\varepsilon_{y y}=\varepsilon_{12}$, the stress components are:

$\sigma_{x x}=\sigma_{y y}=-\frac{Y_{1}}{1-v_{1}} \varepsilon_{12} \quad$ and $\quad \sigma_{z z}=0$

4 Applying the Maxwell relation

$\left(\frac{\Delta S_{\mathrm{V}}^{\mathrm{M}}}{\partial p}\right)_{T}=-\left(\frac{\partial \Delta V_{\mathrm{V}}^{\mathrm{M}}}{\partial T}\right)_{p}$ 


$$
\left(\frac{\partial E_{\mathrm{a}, \mathrm{V}}}{\partial p}\right)_{T} \approx\left(\frac{\Delta H_{\mathrm{V}}^{\mathrm{M}}}{\partial p}\right)_{T}=\Delta V_{\mathrm{V}}^{\mathrm{M}}-\left(\frac{\partial \Delta V_{\mathrm{V}}^{\mathrm{M}}}{\partial T}\right)_{p}
$$

There are only very few data available in literature on the change $\left(\partial \Delta V_{\mathrm{V}}^{\mathrm{M}} / \partial T\right)_{p}$ of the migration volume with temperature. Pressure- and temperature-dependent measurements of the self-diffusion coefficient in single crystalline metallic $\mathrm{Zn}$ yield values for the change of the sum of the migration and the defect formation volume with temperature in the range of $10^{-2}$ and $10^{-3} \mathrm{~cm}^{3} \mathrm{~mol}^{-1} \mathrm{~K}^{-1}$ [54]. In solids $\left(\partial \Delta V_{\mathrm{V}}^{\mathrm{M}} / \partial T\right)_{p}$ is in general small, if there is no change of the transport mechanism in the temperature interval.

When assuming that the change $\left(\partial \Delta V_{\mathrm{V}}^{\mathrm{M}} / \partial T\right)_{p}$ of the migration volume with temperature is small, the right side of Eq. 10 can be approximated only with the migration volume. In this case, a simple linear relation between lattice mismatch $f_{12}$ and the activation energy of ionic conduction in the interfacial region can be derived for a phase boundary with coherent strain proportional to the mismatch:

$E_{\mathrm{a}, \mathrm{V}, \text { int }}-E_{\mathrm{a}, \mathrm{V}, \mathrm{vol}} \sim-\Delta V_{\mathrm{V}}^{\mathrm{M}} f_{12}$

In case of dilatative strain $\left(f_{12}>0\right)$, a decrease of the interfacial activation energy compared to the bulk is expected. For compressive strain $\left(f_{12}<0\right)$ the activation energy in the interface region should increase.

If a distinct value for the lattice mismatch is exceeded, a semicoherent phase boundary is energetically more favourable. The coherent strain is localised by the introduction of (edge-type) mismatch dislocations in the interface with a mutual distance $D$. The critical value depends on the elastic properties and on the geometry of the adjacent crystallites. For thin columnar crystallites, where the extent of the phase boundary is much smaller than the dimension perpendicular to the interface, the critical value for the mismatch is higher compared to large and flat crystallites, where the extent of the phase boundary is larger than the dimension perpendicular to the interface. As already discussed above, in the former case strain relaxation by shear of the crystallites is possible.

Each misfit dislocation can act as a fast pipe-like transport path, because of fast transport processes in the less densely packed dislocation core and the dipol-like strain field with a dilatative strained region. In case of a semicoherent phase boundary with a regular network of mismatch dislocations, the interface conductivity $\sigma_{\mathrm{O}^{2-} \text {,int }}$ should be linearly dependent on the dislocation density $1 / D$. If the lattice mismatch is only compensated by mismatch dislocations, the dislocation density $1 / D$ is also linearly dependent on the mismatch $f_{12}$ :
$\sigma_{\mathrm{O}^{2-}, \mathrm{int}}-\sigma_{\mathrm{O}^{2-}, \mathrm{vol}} \sim \frac{1}{D}=\frac{\left|f_{12}\right|}{|\mathbf{b}|}$

Here, $|\mathbf{b}|$ is the absolute value of the Burgers vector of the dislocations. In a semicoherent phase boundary, the activation energy $E_{\mathrm{a}, \mathrm{V}, \text { int }}$ for interfacial transport converge with increasing dislocation density $1 / D$ to the activation energy for ionic transport in dislocation lines. Because of the lower packing density in the dislocation core and the dilatative strained lattice region, it is lower than the activation energy $E_{\mathrm{a}, \mathrm{V}, \mathrm{vol}}$ in the bulk.

\section{Model systems with variable lattice mismatch}

An important prerequisite for the systematic investigation of the influence of interface structure on interfacial transport properties is the availability of model systems with defined geometry, comparable bulk structures and properties. The model systems should have a variable lattice misfit to obtain a series of different types of interfaces. For this purpose we use multilayered samples, consisting of alternating layers of an ionic conductor and different insulators. The insulators should completely block ionic and electronic transport. In a multilayer sample, the area of the phase boundaries and the orientation of the adjacent crystallites are easily determined. In contrast to composite systems composed from randomly oriented particles like sintered ceramic powders, any measured effect on the ionic conductivity can safely be attributed to a distinct type of interface. In contrast to single layer systems, the total cross section of the ionic conducting phase can be kept constant to avoid a high electrical resistance of the sample. In Table 1 a survey of experimental studies on ionic conduction in thin-film systems is given. In the literature, investigations can be found on single and multilayer systems consisting of $\mathrm{F}^{-}, \mathrm{O}^{2-}, \mathrm{H}^{+}, \mathrm{Li}^{+}$or $\mathrm{Ag}^{+}$ion conductors. The majority of the studies were performed on single-layer systems.

\section{Ionic conduction in multilayer systems}

As depicted in Fig. 1, for a multilayer system two independent conduction paths can be distinguished when the interface region has a distinct width $\delta$ and a local ionic conductivity $\sigma_{\text {int }}$ different from the bulk conductivity $\sigma_{\mathrm{vol}}$. One obtains a linear relation between the total conductivity $\sigma_{\text {tot }}$ parallel to the phase boundaries and the phase boundary density, respectively the reciprocal thickness $1 / d$ of the ionic conducting layers [19, 20]:

$\sigma_{\mathrm{tot}}=\sigma_{\mathrm{vol}}+2 \delta\left(\sigma_{\mathrm{int}}-\sigma_{\mathrm{vol}}\right) \frac{1}{d}$ 
Table 1 A survey on the experimental studies on ionic conduction in thin-film systems given in the literature

\begin{tabular}{|c|c|c|c|}
\hline System on substrate & Mobile species & Citation & Remark \\
\hline $\mathrm{CaF}_{2} / \mathrm{BaF}_{2}$ on $\mathrm{Al}_{2} \mathrm{O}_{3}$ substrate & $\mathrm{F}^{-}$ & $\begin{array}{l}\text { Sata et al. [12] } \\
\text { Jin-Phillipp et al. [13] }\end{array}$ & Multilayer \\
\hline YSZ on (001) MgO substrate & $\mathrm{O}^{2-}$ & $\begin{array}{l}\text { Kosacki et al. }[14,15] \\
\text { Karthikeyan et al. [16] }\end{array}$ & Single layer \\
\hline $\mathrm{YSZ}$ on $\mathrm{Al}_{2} \mathrm{O}_{3}$ substrate & $\mathrm{O}^{2-}$ & Kosacki et al. [17] & Single layer \\
\hline $\mathrm{YSZ} \mathrm{SrTiO}_{3}$ on (001) $\mathrm{SrTiO}_{3}$ substrate & $\mathrm{O}^{2-}$ & Garcia-Barriocanal et al. [18] & Trilayer \\
\hline $\mathrm{YSZ} / \mathrm{Y}_{2} \mathrm{O}_{3}$ on $(0001) \mathrm{Al}_{2} \mathrm{O}_{3}$ substrate & $\mathrm{O}^{2-}$ & Korte et al. [19] & Multilayer \\
\hline $\mathrm{CSZ} / \mathrm{Al}_{2} \mathrm{O}_{3}$ on $(0001) \mathrm{Al}_{2} \mathrm{O}_{3}$ substrate & $\mathrm{O}^{2-}$ & Peters et al. [20] & Multilayer \\
\hline CGO on (001) $\mathrm{MgO}$ substrate & $\mathrm{O}^{2-}$ & Chen et al. [21] & Single layer \\
\hline $\mathrm{CGO}$ on $\mathrm{Al}_{2} \mathrm{O}_{3}$ substrate & $\mathrm{O}^{2-}$ & $\begin{array}{l}\text { Suzuki et al. [22] } \\
\text { Rupp et al. [23] }\end{array}$ & Single layer \\
\hline $\mathrm{CeO}_{2}$ on $\mathrm{Al}_{2} \mathrm{O}_{3}$ substrate & $\mathrm{O}^{2-}$ & $\begin{array}{l}\text { Kosacki et al. [17] } \\
\text { Rupp et al. [23] }\end{array}$ & Single layer \\
\hline GSZ/CGO on $\mathrm{Al}_{2} \mathrm{O}_{3}$ substrate & $\mathrm{O}^{2-}$ & Azad et al. [24] & Multilayer \\
\hline $\mathrm{SrZr}_{0,95} \mathrm{Y}_{0,05} \mathrm{O}_{3} / \mathrm{SrTiO}_{3}$ on $(001) \mathrm{MgO}$ substrate & $\mathrm{H}^{+}$ & Kuwata et al. [25] & Multilayer \\
\hline $\mathrm{LiI}$ on $\mathrm{Al}_{2} \mathrm{O}_{3}$ substrate & $\mathrm{Li}^{+}$ & Lubben et al. [26] & Single layer \\
\hline$\beta$ - $\mathrm{LiAlSiO}_{4}$ on $\mathrm{SiO}_{2}$ glas & $\mathrm{Li}^{+}$ & Shin-ichi et al. [27] & Single layer \\
\hline $\mathrm{AgI}$ on $\mathrm{SiO}_{2}$ glas & $\mathrm{Ag}^{+}$ & Furusawa et al. [28] & Single layer \\
\hline
\end{tabular}

Studies on multilayer as well as on single layer systems can be found (CGO: $\mathrm{Gd}_{2} \mathrm{O}_{3}$ stabilised $\mathrm{CeO}_{2}$, GSZ: $\mathrm{Gd}_{2} \mathrm{O}_{3}$ stabilised $\mathrm{ZrO}_{2}$ )

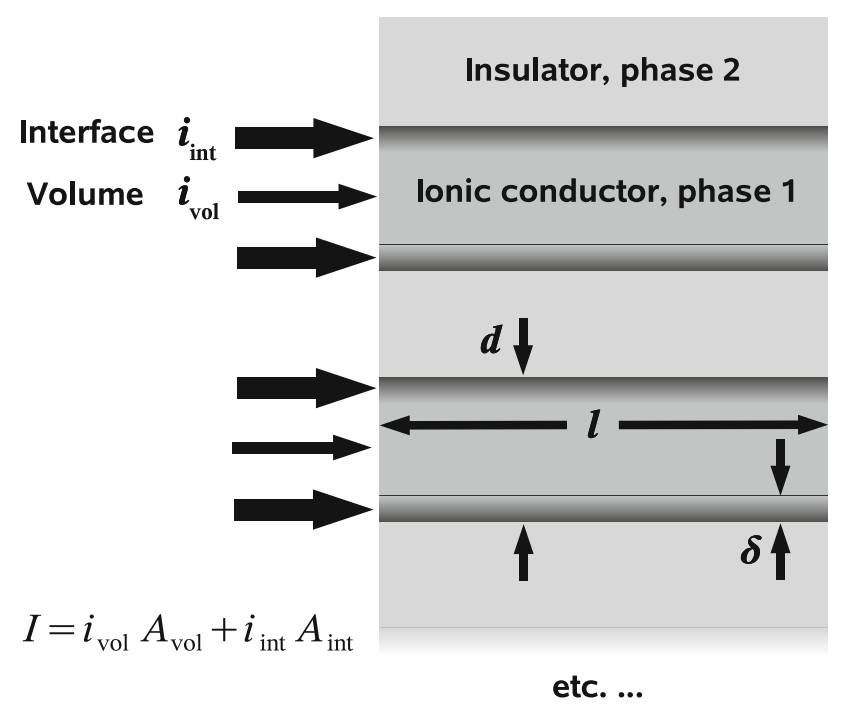

Fig. 1 Ionic conduction in a multilayered system. The thickness of the ionic conducting layers is $d$, and the thickness of the interface region in the ionic conductor is $\delta$. The regions in the ionic conductor close to the interface exhibit an ionic conductivity $\sigma_{\text {int }}$, which is different from the bulk conductivity $\sigma_{\mathrm{vol}}$. The total current through the system is $I$, the current density through the bulk regions is $i_{\mathrm{vol}}$ and through the interface regions $i_{\text {int }}$. The total cross section of the bulk areas is $A_{\mathrm{vol}}$ and of the interface regions $A_{\text {int }}$

The total conductivity $\sigma_{\text {tot }}$ applies only to the total cross section $A$ of the ionic conducting phases. By measuring the total conductivity $\sigma_{\text {tot }}$ of multilayer systems with different layer thickness $d$ the (relative) interfacial conductance $\delta\left(\sigma_{\mathrm{int}}-\sigma_{\mathrm{vol}}\right)$ can be isolated by analysing the slope when plotting $\sigma_{\text {tot }}$ against the density of phase boundaries $1 / d$. Information on the activation energy $E_{\mathrm{a} \text {,int }}$ for the interfacial transport can be gained in an Arrhenius plot from the temperature dependence.

\section{Stabilised $\mathrm{ZrO}_{2}$ and bixbyite type rare earth metal oxides $\left(\mathrm{RE}_{2} \mathrm{O}_{3}\right)$}

We choose cubic stabilised $\mathrm{ZrO}_{2}$ (CSZ and YSZ) as ionic conductor. In these oxides the Debye length is generally very small, because of the high concentration $c_{\mathrm{V}}^{\text {ext }}$ of mobile oxygen vacancies of about $10^{-3} \mathrm{~mol} \mathrm{~cm} \mathrm{~cm}^{-3}$. Taking a dielectric constant of about 25 to 35 into account, we obtain for a temperature of $500^{\circ} \mathrm{C}(773 \mathrm{~K})$ a Debye length in the order of $1 \AA[55,56]$. In this case space charge regions cannot be distinguished from the interface core.

When combining cubic stabilised $\mathrm{ZrO}_{2}$ in a multilayer structure with an insulating oxide of fluorite or fluoriterelated structure with a comparable lattice constant, preferentially coherent or semicoherent phase boundaries are formed. An ideal choice are the sesqui-oxides $\mathrm{RE}_{2} \mathrm{O}_{3}$ ( $\mathrm{RE}=$ rare earth metal cation) of the heavy rare earth elements, as well as scandium and yttrium. The oxides $\mathrm{Yb}_{2} \mathrm{O}_{3}$ and $\mathrm{Eu}_{2} \mathrm{O}_{3}$ should not be taken into account because $\mathrm{Yb}$ and $\mathrm{Eu}$ also exist as divalent cations. This allows a possible oxygen substoichiomety and electronic conductivity.

These oxides crystallise in the cubic bixbyite structure. The bixbyite structure can be derived from the fluorite structure by 
doubling the lattice constants, introducing structural (immobile) oxygen vacancies and by a slight relaxation of the other atomic positions. The lattice constant is just about twice the lattice constant of stabilised $\mathrm{ZrO}_{2}$, resulting in lattice mismatches $f_{\mathrm{ZrO}_{2} / \mathrm{RE}_{2} \mathrm{O}_{3}}$ in the range of $\pm 5 \%$.

We have investigated the multilayer system $\mathrm{YSZ} / \mathrm{Y}_{2} \mathrm{O}_{3}$ on (0001) $\mathrm{Al}_{2} \mathrm{O}_{3}$ substrates with a mismatch $f_{\mathrm{ZrO}_{2} / \mathrm{RE}_{2} \mathrm{O}_{3}}$ of $3.09 \%$ [19]. Samples with layer thicknesses down to $17 \mathrm{~nm}$ were prepared. First limited results on oxygen-ion conductivity and activation energy are available for the multilayer systems $\mathrm{YSZ} / \mathrm{Lu}_{2} \mathrm{O}_{3}$ and $\mathrm{YSZ} / \mathrm{Sc}_{2} \mathrm{O}_{3}$ on $(0001)$ $\mathrm{Al}_{2} \mathrm{O}_{3}$ with mismatches $f_{\mathrm{ZrO}_{2} / \mathrm{RE}_{2} \mathrm{O}_{3}}$ of 1.02 and $-4.28 \%$ [57]. Future investigations of the multilayer system YSZ/ $\mathrm{Gd}_{2} \mathrm{O}_{3}$ on (0001) $\mathrm{Al}_{2} \mathrm{O}_{3}$ with a mismatch $f_{\mathrm{ZrO}_{2} / \mathrm{RE}_{2} \mathrm{O}_{3}}$ of $5.08 \%$ are planed. All samples were prepared by pulsed laser deposition (PLD). The experimental details are described in the given references. Using (0001) $\mathrm{Al}_{2} \mathrm{O}_{3}$ substrates, one finds only one strongly preferred orientation for all mentioned systems:

$$
\text { (111) YSZ \| (111) } \mathrm{RE}_{2} \mathrm{O}_{3} \| \text { (0001) } \mathrm{Al}_{2} \mathrm{O}_{3}
$$

All multilayered samples have a columnar crystallite structure, which is independent from the phase boundaries (see Fig. 2). Within one column the YSZ and the $\mathrm{RE}_{2} \mathrm{O}_{3}$ crystallites have the same azimutal orientation. Partially, the columns are extended across the whole thickness of the thin-film system. According to the sixfold symmetry of the (0001) $\mathrm{Al}_{2} \mathrm{O}_{3}$ and the threefold symmetry of the (111) $\mathrm{RE}_{2} \mathrm{O}_{3}$ plane, two azimutal variants exist:
a) [1110] YSZ \| [1110] $\mathrm{RE}_{2} \mathrm{O}_{3} \|[\overline{1} 10] \mathrm{Al}_{2} \mathrm{O}_{3}$
b) $[1 \overline{1} 0] \mathrm{YSZ}\left\|[1 \overline{1} 0] \mathrm{RE}_{2} \mathrm{O}_{3}\right\|[\overline{1} 10] \mathrm{Al}_{2} \mathrm{O}_{3}$

In case of the multilayer system $\mathrm{YSZ} / \mathrm{Lu}_{2} \mathrm{O}_{3}$ also other orientations like (011) YSZ $\|(011) \mathrm{Lu}_{2} \mathrm{O}_{3}$ can be found [57]. All investigated $\mathrm{YSZ} / \mathrm{RE}_{2} \mathrm{O}_{3}$ systems have semicoherent to (quasi-)coherent interfaces. Using HRTEM, no disordered transition region can be observed between $\mathrm{YSZ}$ and $\mathrm{RE}_{2} \mathrm{O}_{3}$.

The multilayer systems $\mathrm{YSZ} / \mathrm{Tm}_{2} \mathrm{O}_{3}, \mathrm{YSZ} / \mathrm{Er}_{2} \mathrm{O}_{3}, \mathrm{YSZ} /$ $\mathrm{Ho}_{2} \mathrm{O}_{3}, \mathrm{YSZ} / \mathrm{Dy}_{2} \mathrm{O}_{3}$ and $\mathrm{YSZ} / \mathrm{Tb}_{2} \mathrm{O}_{3}$ with lattice misfits in the range between 1.96 and $4.31 \%$ have not been investigated yet. The lattice mismatches of these systems could complete the parameter range between $\mathrm{YSZ} / \mathrm{Y}_{2} \mathrm{O}_{3}$ and $\mathrm{YSZ} / \mathrm{Lu}_{2} \mathrm{O}_{3}$. In Table 2 a survey is given on all systems discussed and investigated in this paper.

\section{Stabilised $\mathrm{ZrO}_{2}$ and oxides with different lattice structure}

A multilayer system with incoherent phase boundaries can be obtained by combining cubic stabilised $\mathrm{ZrO}_{2}$ with hexagonal $\mathrm{Al}_{2} \mathrm{O}_{3}$, possessing completely different symmetry and lattice spacings. After preparing a multilayer

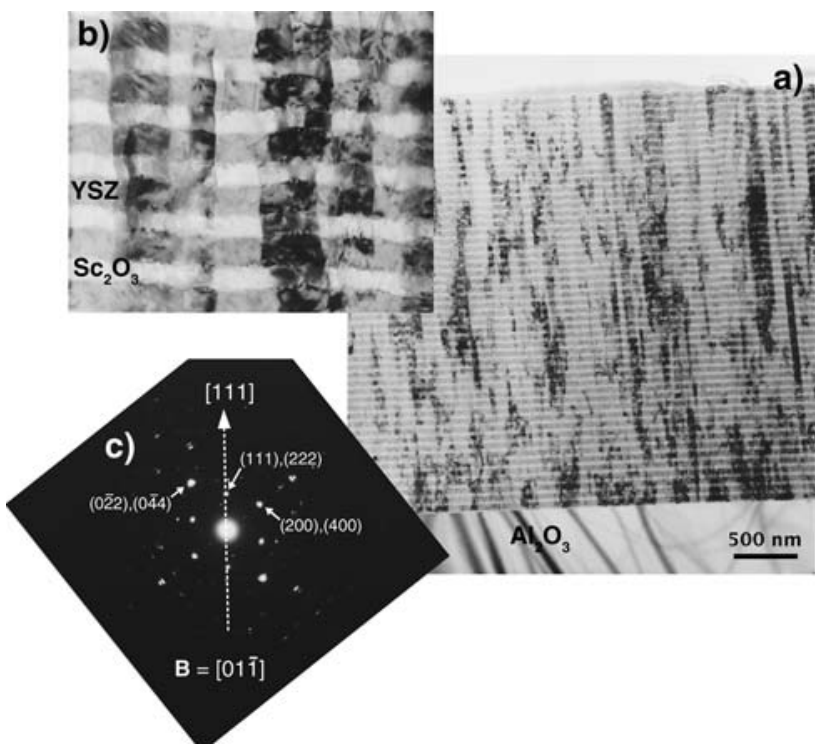

Fig. 2 a TEM microslides (BF) of an $\mathrm{YSZ} / \mathrm{Sc}_{2} \mathrm{O}_{3}$ multilayer system on an (0001) $\mathrm{Al}_{2} \mathrm{O}_{3}$ substrate with $n=50$ YSZ layers. $\mathbf{b}$ is a higher magnified detail of $\mathbf{a}$ and $\mathbf{c}$ a SAED of a column in the multilayered thin film close to the surface with an aperture of $0.2 \mu \mathrm{m}$. The vector in direction of the electron beam is denoted with $\mathbf{B}$. The reflections of $\mathrm{YSZ}$ and $\mathrm{Sc}_{2} \mathrm{O}_{3}$ are very close together. The first given indices belong to $\mathrm{YSZ}$, the second to $\mathrm{Sc}_{2} \mathrm{O}_{3}$

system of CSZ and $\mathrm{Al}_{2} \mathrm{O}_{3}$ on a highly indexed $\mathrm{Al}_{2} \mathrm{O}_{3}$ substrate, we did not find any orientation relations between the layers and the substrate. Samples with layer thicknesses down to $51 \mathrm{~nm}$ were prepared. By using HRTEM, a structurally disordered transition region between CSZ and $\mathrm{Al}_{2} \mathrm{O}_{3}$ was detected [20].

Experimental studies on a thin-film system consisting of oxygen-ion conducting stabilised $\mathrm{ZrO}_{2}$ and other insulating oxide with cubic lattice structure have been reported by Kosacki et al. [14, 15], Karthikeyan et al. [16] and GarciaBarriocanal et al. [18] (see Table 2).

In the studies from Kosacki et al. and Karthikeyan et al., the oxygen-ion conductivity and activation energy of single thin films of YSZ on (001) MgO substrates were determined. The thickness of the YSZ thin films was varied between $2 \mu \mathrm{m}$ and $15 \mathrm{~nm}$. Kosacki et al. found strict orientation relations between the YSZ crystallites in the layer and the $\mathrm{MgO}$ substrate (rock salt structure):

$$
\begin{aligned}
& \text { (001) YSZ } \| \text { (001) } \mathrm{MgO} \\
& \text { [100] YSZ } \|[100] \mathrm{MgO}
\end{aligned}
$$

In case of a 1:1 match between the (100) and (010) planes in the (001) oriented interface, a lattice mismatch of $-18.01 \%$ results. The authors state that they found no indication for a dislocation network in the interface. Because of the high misfit that cannot be compensated solely by elastic strain, we consider this statement as doubtful. 
Table 2 Survey over all discussed multilayered and single-layered systems based on stabilised $\mathrm{ZrO}_{2}$ as ionic conducting phase

\begin{tabular}{|c|c|c|c|c|c|c|c|c|}
\hline $\begin{array}{l}\text { Substrate/multilayer } \\
\text { system }\end{array}$ & $\begin{array}{l}\text { Phase } \\
\text { boundary }\end{array}$ & $\begin{array}{l}\text { Dislocation } \\
\text { density, } D(\mathrm{~cm})\end{array}$ & $f_{\mathrm{ZrO}_{2} / \mathrm{Ins}}$ & $\begin{array}{l}T \\
\left({ }^{\circ} \mathrm{C}\right)\end{array}$ & $\sigma_{\mathrm{tot}}^{\max } / \sigma_{\mathrm{vol}}$ & $\begin{array}{l}\delta\left(\sigma_{\mathrm{int}}-\sigma_{\mathrm{vol}}\right) \\
(\mathrm{S})\end{array}$ & $\begin{array}{l}\left(E_{\mathrm{a}, \mathrm{tot}}^{\max }-E_{\mathrm{a}, \mathrm{vol}}\right) \\
(\mathrm{eV})\end{array}$ & Remarks \\
\hline $\begin{array}{r}(0001) \mathrm{Al}_{2} \mathrm{O}_{3} / \mathrm{Sc}_{2} \mathrm{O}_{3} / \\
\quad\left[\mathrm{YSZ} / \mathrm{Sc}_{2} \mathrm{O}_{3}\right] \times n\end{array}$ & Semicoherent & $\begin{array}{l}\text { Only in some } \\
\text { crystallites few } \\
\text { dislocations, } \\
<1 \times 10^{6}\end{array}$ & $\begin{array}{r}-4.28 \% \\
\quad(2: 1)\end{array}$ & 560 & $\begin{array}{l}0.6 \\
\quad(15 \mathrm{~nm})\end{array}$ & $\begin{array}{c}-2.0 \times 10^{-11} \\
(15 \mathrm{~nm})\end{array}$ & $0.09(15 \mathrm{~nm})$ & $\begin{array}{l}\text { First experimental } \\
\text { studies, } \\
\text { Schichtel et al. } \\
{[57]}\end{array}$ \\
\hline $\begin{array}{c}(0001) \mathrm{Al}_{2} \mathrm{O}_{3} / \mathrm{Lu}_{2} \mathrm{O}_{3} / \\
{\left[\mathrm{YSZ} / \mathrm{Lu}_{2} \mathrm{O}_{3}\right] \times n}\end{array}$ & (Quasi-) coherent & $\begin{array}{l}\text { Only in some } \\
\text { crystallites very } \\
\text { few dislocations }\end{array}$ & $1.02 \%(2: 1)$ & 560 & $1(20 \mathrm{~nm})$ & $\begin{array}{l}\text { no tendency } \\
\quad(20 \mathrm{~nm})\end{array}$ & $0(20 \mathrm{~nm})$ & $\begin{array}{l}\text { First experimental } \\
\text { studies, } \\
\text { Schichtel et al. } \\
\text { [57] }\end{array}$ \\
\hline $\begin{array}{c}(0001) \mathrm{Al}_{2} \mathrm{O}_{3} / \mathrm{Tm}_{2} \mathrm{O}_{3} / \\
{\left[\mathrm{YSZ} / \mathrm{Tm}_{2} \mathrm{O}_{3}\right] \times n}\end{array}$ & Semicoherent? & & $1.96 \%(2: 1)$ & & & & & \\
\hline $\begin{array}{c}(0001) \mathrm{Al}_{2} \mathrm{O}_{3} / \mathrm{Er}_{2} \mathrm{O}_{3} / \\
{\left[\mathrm{YSZ} / \mathrm{Er}_{2} \mathrm{O}_{3}\right] \times n}\end{array}$ & Semicoherent? & & $2.43 \%(2: 1)$ & & & & & \\
\hline $\begin{array}{c}(0001) \mathrm{Al}_{2} \mathrm{O}_{3} / \mathrm{Y}_{2} \mathrm{O}_{3} / \\
{\left[\mathrm{YSZ} / \mathrm{Y}_{2} \mathrm{O}_{3}\right] \times n}\end{array}$ & Semicoherent & $\begin{array}{l}\text { Only in some } \\
\text { crystallites few } \\
\text { dislocations, } \\
<1 \times 10^{6}\end{array}$ & $3.09 \%(2: 1)$ & 560 & $1.3(24 \mathrm{~nm})$ & $\begin{array}{c}6.9 \times 10^{-11} \\
\quad(24 \mathrm{~nm})\end{array}$ & $-0.14(24 \mathrm{~nm})$ & $\begin{array}{l}\text { Experimental } \\
\text { studies, Korte } \\
\text { et al. [19] }\end{array}$ \\
\hline $\begin{array}{r}(0001) \mathrm{Al}_{2} \mathrm{O}_{3} / \mathrm{Ho}_{2} \mathrm{O}_{3} / \\
{\left[\mathrm{YSZ} / \mathrm{Ho}_{2} \mathrm{O}_{3}\right] \times n}\end{array}$ & Semicoherent? & & $3.11 \%(2: 1)$ & & & & & \\
\hline $\begin{array}{r}(0001) \mathrm{Al}_{2} \mathrm{O}_{3} / \mathrm{Dy}_{2} \mathrm{O}_{3} / \\
{\left[\mathrm{YSZ} / \mathrm{Dy}_{2} \mathrm{O}_{3}\right] \times n}\end{array}$ & Semicoherent? & & $3.70 \%(2: 1)$ & & & & & \\
\hline $\begin{array}{r}(0001) \mathrm{Al}_{2} \mathrm{O}_{3} / \mathrm{Tb}_{2} \mathrm{O}_{3} / \\
{\left[\mathrm{YSZ} / \mathrm{Tb}_{2} \mathrm{O}_{3}\right] \times n}\end{array}$ & Semicoherent? & & $4.31 \%(2: 1)$ & & & & & \\
\hline $\begin{array}{c}(0001) \mathrm{Al}_{2} \mathrm{O}_{3} / \mathrm{Gd}_{2} \mathrm{O}_{3} / \\
{\left[\mathrm{YSZ} / \mathrm{Gd}_{2} \mathrm{O}_{3}\right] \times n}\end{array}$ & Semicoherent? & & $5.08 \%(2: 1)$ & & & & & \\
\hline \multirow[t]{3}{*}{ (001) $\mathrm{MgO} / \mathrm{YSZ}$} & Semicoherent & $\begin{array}{l}\text { Regular network, } \\
\quad 9.1 \times 10^{6}\end{array}$ & $\begin{array}{c}-18.01 \% \\
(1: 1)\end{array}$ & 550 & $37(17 \mathrm{~nm})$ & & $-0.5(17 \mathrm{~nm})$ & \multirow{3}{*}{$\begin{array}{l}\text { Experimental } \\
\text { studies, Kosacki } \\
\text { et al. }[14,15] \\
\text { and Karthikeyan } \\
\text { et al. }[16], \\
\text { samples with a } \\
\text { single YSZ layer }\end{array}$} \\
\hline & & & $2.49 \%(4: 5)$ & & $10(29 \mathrm{~nm})$ & $\begin{array}{l}2.5 \times 10^{-8} \\
(29 \mathrm{~nm})\end{array}$ & & \\
\hline & & & $\begin{array}{r}-1.61 \% \\
(5: 6)\end{array}$ & & $4.6(58 \mathrm{~nm})$ & $\begin{array}{c}7.0 \times 10^{-9} \\
(58 \mathrm{~nm})\end{array}$ & & \\
\hline $\begin{array}{l}(22 \overline{4} 3) \mathrm{Al}_{2} \mathrm{O}_{3} /[\mathrm{CSZ} / \\
\left.\mathrm{Al}_{2} \mathrm{O}_{3}\right] \times n\end{array}$ & $\begin{array}{l}\text { Presumely } \\
\quad \text { incoherent }\end{array}$ & $\begin{array}{l}\text { Disordered } \\
\quad \text { transition region }\end{array}$ & $\begin{array}{l}\text { non- } \\
\quad \text { applicable }\end{array}$ & 575 & $60(39 \mathrm{~nm})$ & $\begin{array}{c}1.3 \times 10^{-9} \\
(39 \mathrm{~nm})\end{array}$ & $\begin{array}{l}-0.5 \text { bzw. }-0.8^{\mathrm{a}} \\
\quad(51 \mathrm{~nm})\end{array}$ & $\begin{array}{l}\text { Experimental } \\
\text { studies, Peters } \\
\text { et al. [20] }\end{array}$ \\
\hline
\end{tabular}

The lattice mismatch $f_{\mathrm{ZrO}_{2} / \text { Ins }}$ is calculated regarding the commensurable ratio given in parentheses (stab. $\mathrm{ZrO}_{2}:$ insul. oxid). Experimental data are given for the already investigated systems. The maximum change of the total ionic conductivity $\sigma_{\mathrm{tot}}^{\max } / \sigma_{\mathrm{vol}}$, the relative interface conductance $\delta\left(\sigma_{\mathrm{int}}-\sigma_{\mathrm{vol}}\right)$ and the maximum change of the activation energy $E_{\mathrm{a}, \text { tot }}^{\max }-E_{\mathrm{a}, \mathrm{vol}}$ are evaluated for the layer thickness $d$ given in parentheses

${ }^{\text {a }}$ Activation energy from an Arrhenius plot using the interface conductance $\delta \sigma_{\text {tot }}$

When using Fourier filtering on the TEM microslides provided by Kosacki et al. [14], the (020) and the (200) YSZ and MgO lattice planes can be highlighted. By doing this, a regular sequence of misfit dislocations in the $\mathrm{YSZ} / \mathrm{MgO}$ interface can be detected. The mutual distance is about 4-5 (020) YSZ planes or 5 to $6(020) \mathrm{MgO}$ planes, i.e. about $1.0-1.3 \mathrm{~nm}$. The component $b_{\|}$of the Burgers vector $\mathbf{b}$ in the image plane is parallel to the interface and can be identified as $1 / 2$ [010] $\mathrm{MgO}$ or $1 / 2$ [100] $\mathrm{MgO}$. There are no components in other directions in the image plane. The length of this Burgers vector component $b_{\|}$is equal to a half of a unit cell (1/2 $\times 4.217 \AA$ ). From a lattice mismatch $f_{\mathrm{ZrO}_{2} / \mathrm{MgO}}$ of $-18.01 \%$ an average distance $D$ of $1.2 \mathrm{~nm}$ can be calculated:
$D=\frac{b_{\|}}{f_{\mathrm{ZrO}_{2} / \mathrm{Ins}}}$

This is in good agreement with the distance that we find in the TEM microslides. Caused by the fourfold symmetry of the (001) $\mathrm{MgO}$ and (001) YSZ planes, a quadratic dislocation network must exist.

The ratio between the lattice constants of YSZ and $\mathrm{MgO}$ is about $4: 5$ to 5:6. Assuming a 4:5 or 5:6 match between the lattice planes by introduction of dislocations, the residual mismatch $f_{\mathrm{ZrO}} / \mathrm{MgO}$ is reduced to 2.49 or $-1.61 \%$. The remaining mismatch might be compensated elastically. The YSZ/(001) MgO phase boundary should be considered as a semicoherent and not as a coherent interface, as incorrectly stated in [14]. 
In the study of Garcia-Barriocanal et al., the oxygen-ion conductivity of trilayer $\mathrm{YSZ} / \mathrm{SrTiO}_{3}$ thin-film systems on (001) $\mathrm{SrTiO}_{3}$ substrates is investigated (cubic perovskite structure). The thickness of the YSZ films was varied between $1 \mathrm{~nm}$ and $62 \mathrm{~nm}$. In this study a total conductivity of the YSZ layers of about 10 to $100 \mathrm{~S} \mathrm{~cm}^{-1}$ is measured. This implies an increase of about eight orders of magnitude compared to the bulk. It is much higher than the results of all other studies. For the given temperature of $300^{\circ} \mathrm{C}$, it is even higher than the ionic conductivity of the structurally disordered $\mathrm{Ag}^{+}$conductors $\mathrm{AgI}$ and $\mathrm{RbAg}_{4} \mathrm{I}_{5}$ (superionic conductors)

The high value of the total conductivity might be also caused by electronic conduction in the $\mathrm{SrTiO}_{3}$ layers and substrate. The electronic partial conductivity can be largely increased by a small oxygen deficit, resulting in a n-type semiconductor. Because it is not clear that only ionic conduction is measured, the results of this study will not be discussed in the framework of this model.

\section{Ionic conductivity of multilayer and thin-film samples}

According to Eq. 13, the total ionic conductivity $\sigma_{\text {tot }}$ of a multilayer or single-layer system can be described by a parallel connection of conduction paths through the bulk and along the phase boundaries. The interfacial conductivity $\sigma_{\text {int }}$ in a composite ionic conductor should increase with increasing dilatative strain $\varepsilon_{\mathrm{ZrO}_{2}}$ /ns and with increasing density $1 / D$ of misfit dislocations, according to the model introduced in "Structural effects on the interfacial ionic conductivity".

The results of our studies on the multilayer systems $\mathrm{YSZ} / \mathrm{Sc}_{2} \mathrm{O}_{3}, \mathrm{YSZ} / \mathrm{Lu}_{2} \mathrm{O}_{3}, \mathrm{YSZ} / \mathrm{Y}_{2} \mathrm{O}_{3}$ and $\mathrm{CSZ} / \mathrm{Al}_{2} \mathrm{O}_{3}$ on (0001) $\mathrm{Al}_{2} \mathrm{O}_{3}$ substrates $[19,20,57]$ as well as the results from Kosacki et al. [14, 15] and Karthikeyan et al. [16] on single YSZ layers on (001) MgO substrates are summarised in Table 2. We compare the maximum change of the total conductivity $\sigma_{\text {tot }}^{\max }$ measured in the (multilayered) thin-film systems with the conductivity $\sigma_{\mathrm{vol}}$ of bulk YSZ (CSZ). Samples with YSZ (CSZ) layers down to 20$40 \mathrm{~nm}$ are taken into account. In the series $\mathrm{YSZ} / \mathrm{Lu}_{2} \mathrm{O}_{3}-$ $\mathrm{YSZ} / \mathrm{Y}_{2} \mathrm{O}_{3}-\mathrm{YSZ} / \mathrm{MgO}-\mathrm{CSZ} / \mathrm{Al}_{2} \mathrm{O}_{3}$, the increase of the total ionic conductivity relative to the bulk $\sigma_{\text {tot }}^{\max } / \sigma_{\text {vol }}$ rises from a factor of about 1 for $\mathrm{YSZ} / \mathrm{Lu}_{2} \mathrm{O}_{3}$ (no effect) to a factor of 60 for $\mathrm{CSZ} / \mathrm{Al}_{2} \mathrm{O}_{3}$. In the limited conductivity data available for the system $\mathrm{YSZ} / \mathrm{Lu}_{2} \mathrm{O}_{3}$, there is no noticeable tendency for $\sigma_{\text {tot }}$ when increasing the phase boundary density $1 / d$. In contrast to the other systems, the total ionic conductivity $\sigma_{\text {tot }}$ for the system $\mathrm{YSZ} / \mathrm{Sc}_{2} \mathrm{O}_{3}$ is decreasing by a factor of 0.6 relative to the bulk when decreasing the thickness of the YSZ layers down to $15 \mathrm{~nm}$.
In nearly the same series, $\mathrm{YSZ} / \mathrm{Lu}_{2} \mathrm{O}_{3}-\mathrm{YSZ} / \mathrm{Y}_{2} \mathrm{O}_{3}-$ $\mathrm{CSZ} / \mathrm{Al}_{2} \mathrm{O}_{3}-\mathrm{YSZ} / \mathrm{MgO}$, the interfacial conductance relative to the bulk $\delta\left(\sigma_{\text {int }}-\sigma_{\text {vol }}\right)$ increases from nearly zero to $2.5 \times 10^{-8} \mathrm{~S}$. The relative interfacial conductance $\delta\left(\sigma_{\mathrm{int}}-\sigma_{\mathrm{vol}}\right)$ is determined from the slope when plotting the total conductivity $\sigma_{\text {tot }}$ versus the reciprocal thickness of the conducting layers 1/d (interface density, see Fig. 3). Again in contrast to the other systems, for the system YSZ/ $\mathrm{Sc}_{2} \mathrm{O}_{3}$ the relative interfacial conductance $\delta\left(\sigma_{\text {int }}-\sigma_{\mathrm{vol}}\right)$ is negative, i.e. the conductivity of the interfacial regions is smaller compared to the bulk.

The results from Kosacki et al. and Karthikeyan et al. cannot simply be compared with the results from studies on multilayer systems. The single YSZ layers used in [14-16] were not covered with a top layer consisting of the substrate material. Thus, the interpretation is hampered by the simultaneous effect of both the free YSZ surface and the YSZ/MgO heterophase boundary. The influence of the conduction path along the free YSZ surface is indicated by an additional experiment by Karthikeyan: No difference in ionic conductivity was observed when a YSZ film with the same thickness was prepared on a (0001) $\mathrm{Al}_{2} \mathrm{O}_{3}$ substrate instead of a (001) $\mathrm{MgO}$ one. Kosacki reports that the activation energy evaluated from the conductivity data is changed when the sample is measured in an atmosphere equilibrated with water. Hence, we conclude that both studies by Kosacki et al. and Karthikeyan et al. do not offer unequivocal data for solid/solid boundaries.

Disregarding these problems, the thin-film system YSZ/ $\mathrm{MgO}$ can be arranged in the series close to the system CSZ/ $\mathrm{Al}_{2} \mathrm{O}_{3}$ with incoherent phase boundaries when comparing the measured interface conductivity data and considering the lattice mismatch and dislocation density.

From the results of these studies, we conclude that systems with the highest mismatch or with incoherent phase boundaries have the highest interfacial conductance $\delta\left(\sigma_{\text {int }}-\right.$ $\left.\sigma_{\mathrm{vol}}\right)$. When considering the values for the interface conductance $\delta\left(\sigma_{\text {int }}-\sigma_{\mathrm{vol}}\right)$ and the maximum change $\sigma_{\text {tot }}^{\max } / \sigma_{\mathrm{vol}}$ of the total conductivity, we also assume for the series YSZ/ $\mathrm{Sc}_{2} \mathrm{O}_{3}-\mathrm{YSZ} / \mathrm{Lu}_{2} \mathrm{O}_{3}-\mathrm{YSZ} / \mathrm{Y}_{2} \mathrm{O}_{3}-\mathrm{YSZ} / \mathrm{MgO}-\mathrm{CSZ} / \mathrm{Al}_{2} \mathrm{O}_{3}$ that there is a strong increase for the (absolute) interfacial conductivity $\sigma_{\text {int }}$.

\section{Activation energy for the interfacial transport}

The total activation energy $E_{\mathrm{a} \text {,tot }}$ for the ionic transport in a multilayer system is a weighted average of the activation energies of the existing conduction paths through the bulk and along the phase boundaries:

$E_{\mathrm{a}, \text { tot }}=f\left(E_{\mathrm{a}, \text { int }}, E_{\mathrm{a}, \mathrm{vol}}\right)$ 

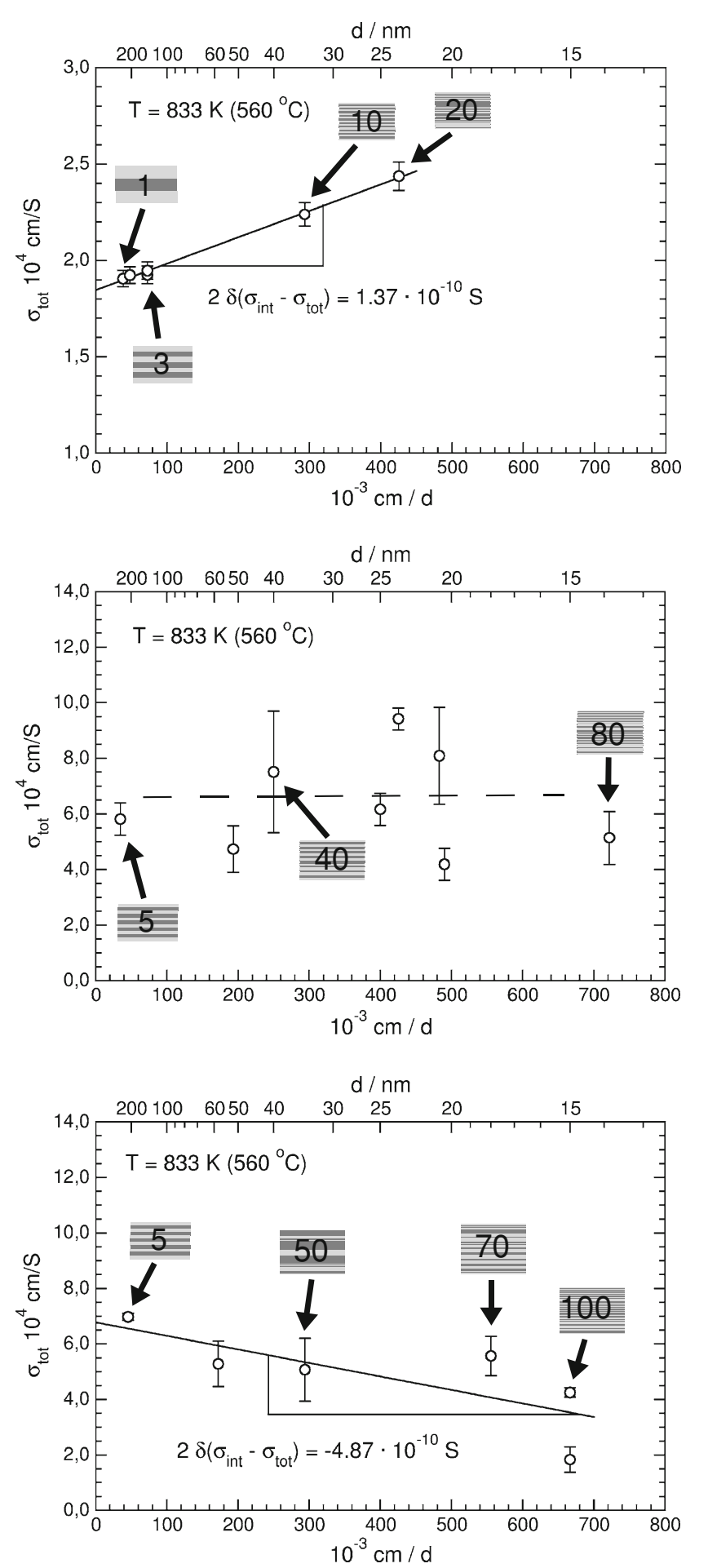

Fig. 3 Plots of the total conductivity $\sigma_{\text {tot }}$ of the multilayer systems $\mathrm{YSZ} / \mathrm{Y}_{2} \mathrm{O}_{3}, \mathrm{YSZ} / \mathrm{Lu}_{2} \mathrm{O}_{3}$ and $\mathrm{YSZ} / \mathrm{Sc}_{2} \mathrm{O}_{3}$ versus the reciprocal thickness $1 / d$ of the YSZ layers

The activation energy for the transport in the bulk is denoted with $E_{\mathrm{a}, \mathrm{vol}}$. The measured total activation energy $E_{\text {a,tot }}$ should converge to the value of the activation energy $E_{\mathrm{a} \text {,int }}$ for transport along phase boundaries with increasing density of phase boundaries $1 / d$, when assuming that the interfacial conductivity is appreciably higher than the bulk conductivity. For very thin layers the interfacial transport should dominate the total transport. According to the simple model, introduced in "Structural effects on the interfacial ionic conductivity “, the activation energy $E_{\mathrm{a}, \text { int }}$ for interfacial transport should decrease with increasing dilatative coherent strain, respectively, with increasing density of mismatch dislocations.

In Table 2 all results for the maximum change $E_{\mathrm{a}, \mathrm{tot}}^{\mathrm{max}}-$ $E_{\mathrm{a}, \mathrm{vol}}$ of the measured total activation energy of the (multilayered) thin-film systems relative to the bulk value of YSZ (CSZ) are summarised, when decreasing the thickness $d$ of the ionic conducting layer(s). Samples with YSZ (CSZ) layers down to 20-50 nm are taken into account. In the series $\mathrm{YSZ} / \mathrm{Lu}_{2} \mathrm{O}_{3}-\mathrm{YSZ} / \mathrm{Y}_{2} \mathrm{O}_{3}-\mathrm{YSZ} / \mathrm{MgO}-\mathrm{CSZ} /$ $\mathrm{Al}_{2} \mathrm{O}_{3}$, a continuously increasing effect can be found. In the system $\mathrm{CSZ} / \mathrm{Al}_{2} \mathrm{O}_{3}$ one finds a change of $-0.5 \mathrm{eV}$, when decreasing the layer thickness down to $51 \mathrm{~nm}$. In the system $\mathrm{YSZ} / \mathrm{Y}_{2} \mathrm{O}_{3}$ the effect on the interfacial activation energy is much smaller. Only a change of $-0.13 \mathrm{eV}$ is determined when decreasing the layer thickness down to $24 \mathrm{~nm}$. In the system $\mathrm{YSZ} / \mathrm{Lu}_{2} \mathrm{O}_{3}$ the measured total activation energy for samples with a layer thickness down to $27 \mathrm{~nm}$ is nearly equal to the bulk value. In contrast to the other systems, in the system $\mathrm{YSZ} / \mathrm{Sc}_{2} \mathrm{O}_{3}$ even a slight increase of the total activation energy $E_{\mathrm{a} \text {,tot }}$ of about $0.09 \mathrm{eV}$ relative to the bulk value can be measured.

In the system YSZ/MgO, which was investigated by Kosacki et al. and Karthikeyan et al. [14-16], the measured change of the total activation energy $E_{\mathrm{a} \text {,tot }}-E_{\mathrm{a} \text {,vol }}$ relative to the bulk is also about $-0.5 \mathrm{eV}$, but for YSZ layers with a thickness of $17 \mathrm{~nm}$. Thus, it can be arranged again in the series between the systems $\mathrm{YSZ} / \mathrm{Y}_{2} \mathrm{O}_{3}$ and $\mathrm{CSZ} / \mathrm{Al}_{2} \mathrm{O}_{3}$. The same effect on the total activation energy occurs for the system $\mathrm{CSZ} / \mathrm{Al}_{2} \mathrm{O}_{3}$ for layers with about twice the thickness as for the system YSZ/MgO.

Because of the same points mentioned in "Ionic conductivity of multilayer and thin-film samples", the interpretation of the data from Kosacki et al. is hampered by the asymmetry of the films. As argued before, the measured effect on $E_{\text {a,tot }}$ might be influenced by conduction processes along the free YSZ surface; thus, it is also averaged with the activation energy of surface conduction.

Systems with the highest (positive) mismatch $f_{\mathrm{ZrO}_{2} / \text { Ins }}$ or with incoherent phase boundaries have the highest decrease for the total activation energy $E_{\mathrm{a}, \mathrm{tot}}^{\max }-E_{\mathrm{a}, \mathrm{vol}}$ relative to the bulk when increasing the density of phase boundaries. According to the measured effect on the total activation energy $E_{\mathrm{a}, \text { tot }}$, we estimate that in the same series, YSZ/ $\mathrm{Sc}_{2} \mathrm{O}_{3}-\mathrm{YSZ} / \mathrm{Lu}_{2} \mathrm{O}_{3}-\mathrm{YSZ} / \mathrm{Y}_{2} \mathrm{O}_{3}-\mathrm{YSZ} / \mathrm{MgO}-\mathrm{CSZ} /$ $\mathrm{Al}_{2} \mathrm{O}_{3}$, there is also a decrease of the activation energy $E_{\mathrm{a}, \text { int }}$ for ionic transport along phase boundaries. 


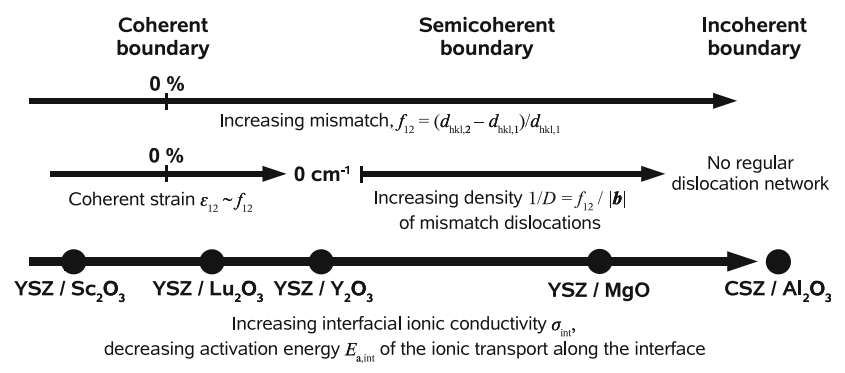

Fig. 4 Classification of the multilayer systems $\mathrm{Sc}_{2} \mathrm{O}_{2} / \mathrm{YSZ}, \mathrm{Lu}_{2} \mathrm{O}_{3} /$ YSZ, $\mathrm{Y}_{2} \mathrm{O}_{3} / \mathrm{YSZ}$ and $\mathrm{Al}_{2} \mathrm{O}_{3} / \mathrm{CSZ}$ investigated in this and in preceding works as well as the single film system $\mathrm{MgO} / \mathrm{YSZ}$ investigated by Kosacki et al. according to the scheme based on interfacial structure from "Structural effects on the interfacial ionic conductivity"

\section{Discussion and conclusions}

The multilayer systems investigated in this and preceding works and the single layer system investigated by Kosacki et al. and Karthikeyan et al. can be arranged in the same series, either considering the measured effect on the total conductivity $\sigma_{\text {tot }}$ or considering the effect on the total activation energy $E_{\mathrm{a}, \text { tot }}$, when increasing the density $1 / d$ of phase boundaries. As depicted in Fig. 4, the series YSZ/ $\mathrm{Sc}_{2} \mathrm{O}_{3}-\mathrm{YSZ} / \mathrm{Lu}_{2} \mathrm{O}_{3}-\mathrm{YSZ} / \mathrm{Y}_{2} \mathrm{O}_{3}-\mathrm{YSZ} / \mathrm{MgO}-\mathrm{CSZ} /$ $\mathrm{Al}_{2} \mathrm{O}_{3}$ corresponds to the change of the mismatch parameter $f_{\mathrm{ZrO}_{2} / \text { Ins }}$ from negative to increasing positve values. We concluded that along with this series the interfacial conductivity $\sigma_{\text {int }}$ is increasing and the activation energy for interfacial transport $E_{\mathrm{a} \text {,int }}$ is decreasing.

For the systems $\mathrm{CSZ} / \mathrm{Al}_{2} \mathrm{O}_{3}$ and $\mathrm{YSZ} / \mathrm{MgO}$, the highest interfacial conductivities $\sigma_{\text {int }}$ and lowest activation energies $E_{\mathrm{a} \text {,int }}$ for interfacial transport can be found. In case of the system $\mathrm{CSZ} / \mathrm{Al}_{2} \mathrm{O}_{3}$ with incoherent phase boundaries, we have a disordered transition region between both phases with a presumably lower packing density than in the bulk. In case of YSZ/MgO, we have a semicoherent phase boundary with a high density of misfit dislocations.

The systems $\mathrm{YSZ} / \mathrm{Y}_{2} \mathrm{O}_{3}$ and $\mathrm{YSZ} / \mathrm{Sc}_{2} \mathrm{O}_{3}$ have presumely semicoherent phase boundaries with a much lower density of misfit dislocations compared to YSZ/MgO. Only in some crystallites misfit dislocations in an irregular arrangement can be found. The average dislocation density in these crystallites is much lower than expected $\left(<10^{6}\right.$ $\left.\mathrm{cm}^{-1}\right)$. The phase boundaries in the system $\mathrm{YSZ} / \mathrm{Lu}_{2} \mathrm{O}_{3}$ can be classified as (quasi-)coherent with nearly no mismatch dislocations in the interface. For the system $\mathrm{YSZ} / \mathrm{Y}_{2} \mathrm{O}_{3}$ with positive lattice mismatch and thus dilatative interfacial strain, an increase of the interfacial conductivity $\sigma_{\text {int }}$ and a decrease of the activation energy $E_{\mathrm{a}, \text { int }}$ for interfacial transport are observed. For the system $\mathrm{YSZ} / \mathrm{Sc}_{2} \mathrm{O}_{3}$ with negative lattice mismatch and thus compressive interfacial strain, a decrease of the interfacial conductivity $\sigma_{\text {int }}$ and an increase of the activation energy $E_{\mathrm{a}, \text { int }}$ for interfacial transport are found. Compared to the systems $\mathrm{CSZ} / \mathrm{Al}_{2} \mathrm{O}_{3}$ and YSZ/MgO with a disordered transition region or with a very high dislocation density, the measured effect is considerably small. Obviously, the few observed mismatch dislocations do not play an important role in the interfacial transport in the systems $\mathrm{YSZ} / \mathrm{Y}_{2} \mathrm{O}_{3}$ and $\mathrm{YSZ} / \mathrm{Sc}_{2} \mathrm{O}_{3}$. In case of the system $\mathrm{YSZ} / \mathrm{Lu}_{2} \mathrm{O}_{3}$ with the best lattice match and thus with the lowest interfacial strain, no difference between interfacial conductivity $\sigma_{\text {int }}$ and activation energy $E_{\mathrm{a}, \text { int }}$ for interfacial transport and the bulk values $\sigma_{\mathrm{vol}}$ and $E_{\mathrm{a}, \mathrm{vol}}$ are noticed.

The interfacial transport properties of the systems YSZ/ $\mathrm{Y}_{2} \mathrm{O}_{3}, \mathrm{YSZ} / \mathrm{Sc}_{2} \mathrm{O}_{3}$ and $\mathrm{YSZ} / \mathrm{Lu}_{2} \mathrm{O}_{3}$ are most likely dominated by the effect of elastic strain. The interfacial transport properties of the systems $\mathrm{CSZ} / \mathrm{Al}_{2} \mathrm{O}_{3}$ and YSZ/ $\mathrm{MgO}$ with high mismatch are mainly affected by atomic packing and mismatch dislocation densities.

The results are in agreement with the considerations in "Structural effects on the interfacial ionic conductivity" according to Eqs. 9 and 11, regarding the dilatative and compressive elastic strain on the activation energy and ionic conductivity. According to Eqs. 7 and 8, a linear dependence of the ratio between the interfacial and the bulk conductivity $\sigma_{\mathrm{int}} / \sigma_{\mathrm{vol}}$ on the lattice mismatch $f_{\mathrm{ZrO}_{2} / \text { Ins }}$ should be observed. When the lattice mismatch $f_{\mathrm{ZrO}_{2} / \mathrm{Ins}}$ for the systems $\mathrm{YSZ} / \mathrm{Y}_{2} \mathrm{O}_{3}, \mathrm{YSZ} / \mathrm{Lu}_{2} \mathrm{O}_{3}$ and $\mathrm{YSZ} / \mathrm{Sc}_{2} \mathrm{O}_{3}$ is completely compensated by elastic strain, it will split up in a multilayer system in two nearly equal fractions in both adjacent phases ${ }^{5}$. Thus, for the relation between $\sigma_{\text {int }} / \sigma_{\mathrm{vol}}$ and $f_{\mathrm{ZrO}_{2} / \text { Ins }}$ should yield:

$\ln \frac{\sigma_{\mathrm{int}}}{\sigma_{\mathrm{vol}}} \approx \frac{1}{3} \frac{\Delta V_{\mathrm{V}_{\mathrm{O}}}^{\mathrm{M}}}{R T} \frac{Y_{\mathrm{YSZ}}}{1-v_{\mathrm{YSZ}}} f_{\mathrm{ZrO}_{2} / \mathrm{Ins}}$

In Fig. 5, the maximum measured change $\sigma_{\mathrm{tot}}^{\max } / \sigma_{\mathrm{vol}}$ of the total conductivity relative to the bulk from Table 2 is used for $\sigma_{\mathrm{int}} / \sigma_{\mathrm{vol}}$. Within the limited accuracy of the measurement, the linear relationship holds.

A slope of about 10.0 can be determined. From the elastic constants $Y_{\mathrm{YSZ}}$ and $v_{\mathrm{YSZ}}$ of about $180 \mathrm{GPa}$ and 0.3 and the migration volume $\Delta V_{\mathrm{V}_{o}^{*}}^{\mathrm{M}}$ of $\mathrm{YSZ}$ of about $2.08 \mathrm{~cm}^{3} \mathrm{~mol}^{-1}$, a theoretic value of 24.6 can be estimated [58, 59]. This discrepancy might be explained by the isotropic approximation of the anisotropic elastic properties of a crystalline material

\footnotetext{
5 In the case that the elastic properties of both thin-film materials are similar, the strain in the interface region is splitting up in equal fractions in the adjacent crystallites:

$\varepsilon_{\mathrm{ZrO}_{2} / \mathrm{Ins}} \approx-\varepsilon_{\mathrm{Ins} / \mathrm{ZrO}_{2}}$

The elastic strain $\varepsilon_{\mathrm{Ins} / \mathrm{ZrO}_{2}}$ in the insulating oxide has necessarily the opposite sign than the elastic strain $\varepsilon_{\mathrm{ZrO}_{2} / \text { Ins }}$ in the conducting phase:

$f_{\mathrm{ZrO}_{2} / \mathrm{Ins}}=\varepsilon_{\mathrm{ZrO}_{2} / \mathrm{Ins}}-\varepsilon_{\mathrm{Ins} / \mathrm{ZrO}_{2}}$
} 


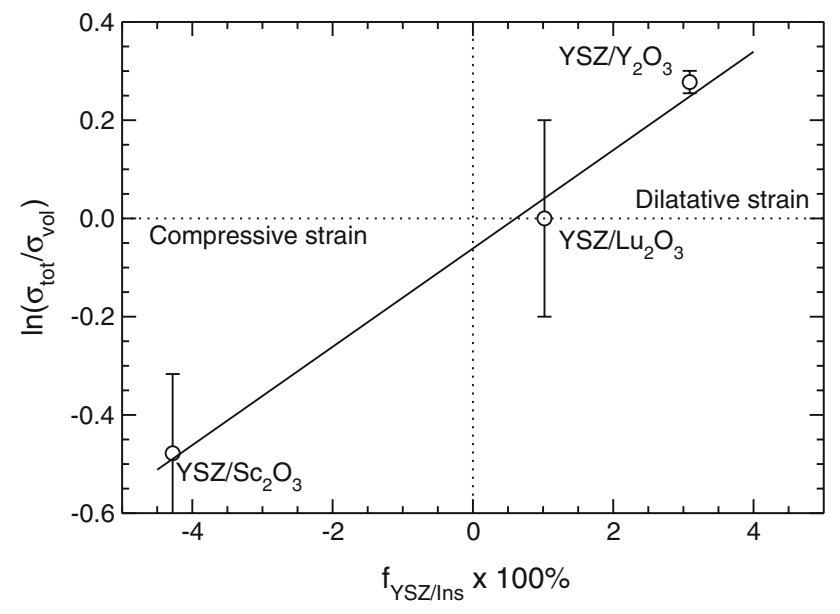

Fig. 5 Plot of the logarithm of the maximum change $\sigma_{\mathrm{tot}}^{\max } / \sigma_{\mathrm{vol}}$ of the total conductivity relative to the bulk conductivity versus the mismatch factor $f_{\mathrm{YSZ} / \mathrm{Ins}}$

and by a partial stress relaxation. The found dislocation density in the systems $\mathrm{Sc}_{2} \mathrm{O}_{2} / \mathrm{YSZ}$ and $\mathrm{Y}_{2} \mathrm{O}_{3} / \mathrm{YSZ}$ is much lower than necessary for a full strain release according to Eq. 14. The measured slope indicates a strain release of about $50 \%$. A more detailed interpretation is not possible, because of the still limited experimental data.

To obtain a more quantitative relation between the lattice mismatch $f_{\mathrm{ZrO}_{2} / \text { Ins }}$ and the interfacial transport parameters according to Eqs. 9 and 11, additional experimental studies are necessary on (multilayered) thin-film systems as listed in Table 2 to complete the present parameter range. According to the model, the experimentally determined dependence on $f_{\mathrm{ZrO}_{2} / \text { Ins }}$ can give an indication of whether the effect on interfacial conductance is caused by purely elastic strain or by fast transport paths along mismatch dislocations.

An uncertainty is the extent $\delta$ of the region with enhanced conductivity close to the boundary. It is not clear if the measured effect on the total conductivity $\sigma_{\text {tot }}$ and the total activation energy $E_{\mathrm{a} \text {,tot }}$ for the multilayer samples with the smallest investigated layer thickness $d$ is already the maximum for this system. The ratio between the ionic transport along phase boundaries and ionic transport in the bulk is not known for each of the (multi-)layered samples. This means it might be possible that they have not reached their limiting values and will further converge to the value of the (true) interfacial conductivity $\sigma_{\text {int }}$ and activation energy $E_{\mathrm{a}, \text { int }}$ for transport along phase boundaries.

Only for the system $\mathrm{CSZ} / \mathrm{Al}_{2} \mathrm{O}_{3}$ was it possible to identify a diffuse transition region in the boundary between both phases with a thickness of about $1 \mathrm{~nm}$ by HRTEM. However, this transition region must not be identical to the extent $\delta$ of the high conducting interface region, because the effect of strain fields has to be taken into account. At the moment, for none of the investigated systems can the width $\delta$ be determined only based on the present data. For the multilayer systems $\mathrm{YSZ} / \mathrm{Lu}_{2} \mathrm{O}_{3}, \mathrm{YSZ} / \mathrm{Y}_{2} \mathrm{O}_{3}$ and CSZ/ $\mathrm{Al}_{2} \mathrm{O}_{3}$, the region with enhanced conductivity is surely thinner than $15-20 \mathrm{~nm}$, when considering the range of the linear dependence of $\sigma_{\mathrm{tot}}$ on $1 / d$.

For a multilayer system with layer thickness $d$ smaller than the double extent $2 \delta$ of the interface region, non-linear effects can be expected for the total conductivity $\sigma_{\text {tot }}$. The functional dependence of $\sigma_{\text {tot }}$ for layer thickness $d$ smaller than $2 \delta$ depends on the structure and constitution of the interface region. In case of strain fields, one should expect a mobility gradient for the charge carriers. For such very thin layers it is also possible that a second polymorphic phase of the ionic conductor with different transport properties is stabilised, due to the change in free enthalpy of the system by the strain fields. For the composite system $\mathrm{AgI} / \mathrm{Al}_{2} \mathrm{O}_{3}$, this is reported by Lee et al. [60]. This could lead to discontinuous changes of $\sigma_{\text {tot }}$ with decreasing thickness $d$. Moreover, depending on the interface and the surface energies, it is possible that there is a minimal thickness for obtaining a continuous layer for a distinct thin-film system. This would lead to percolation phenomena below a critical layer thickness.

Acknowledgments We thank the State of Hessen for financial support (NS, AP, CK). The financial support by the FCI (Funds of the Chemical Industry) is also acknowledged.

\section{References}

1. Robertson J (2006) Rep Prog Phys 69:327-396

2. Locquet J-P, Marchiori C, Sousa M, Fompeyrine J, Seo JW (2006) J Appl Phys 100:051610

3. Dawber M, Rabe KM, Scott JF (2005) Rev Mod Phys 77:1083

4. Setter N, Damjanovic D, Eng L, Fox G, Gevorgian S, Hong S, Kingon A, Kohlstedt H, Park NY, Stephenson GB, Stolitchnov I, Taganstev AK, Taylor DV, Yamada T, Streiffer S (2006) J Appl Phys 100:051606

5. Akbar S, Dutta P, Lee C (2006) Int J Appl Ceram Technol 3(4): 302-311

6. Grünberg P, Bürgler DE, Dassow H, Rata AD, Schneider CM (2007) Acta Mater 55(4):1171-1182

7. Haile SM (2003) Acta Mater 51(19):5981-6000

8. Ormerod RM (2003) Chem Soc Rev 32:17-28

9. Liang CC, Mallory PR and Co (1973) J Electrochem Soc 120(10):1289-1292

10. Atkinson A (1984) Solid State Ionics 12:309-320

11. Beniere F, Reddy KV (1999) J Phys Chem Solids 60(6):839-847

12. Sata N, Jin-Philipp NY, Eberl K, Maier J (2002) Solid State Ionics 154-155:497-502

13. Jin-Phillipp NY, Sata N, Maier J, Scheu C, Hahn K, Kelsch M, R"uhle M (2004) J Chem Phys 120(5):2375-2381

14. Kosacki I, Rouleau CM, Becher PF, Bentley J, Lowndes DH (2004) Electrochem Solid State Lett 7(12): A459-A461

15. Kosacki I, Rouleau CM, Becher PF, Bentley J, Lowndes DH (2005) Solid State Ionics 176(13-14):1319-1326

16. Karthikeyan A, Chang C-L, Ramanathan S (2006) Appl Phys Lett 89:183116 
17. Kosacki I, Suzuki T, Petrovsky V, Anderson H (2000) Solid State Ionics 136-137:1225-1233

18. Garcia-Barriocanal J, Riviera-Calzada A, Varela M, Sefrioui Z, Iborra E, Leon C, Pennycook SJ, Santamaria J (2008) Science 321:676-680

19. Korte C, Peters A, Hesse D, Zakharov N, Janek J (2008) Phys Chem Chem Phys 10:4623-4635. doi:10.1039/b801675e

20. Peters A, Korte C, Hesse D, Zakharov N, Janek J (2007) Solid State Ionics 178:67-76

21. Chen L, Chen CL, Chen X, Donner W, Liu SW, Lin Y, Huang DX, Jacobson AJ (2003) Appl Phys Lett 83(23):4737-4739

22. Suzuki T, Kosacki I, Anderson HU (2002) Solid State Ionics 151:111-121

23. Rupp JLM, Gauckler LJ (2006) Solid State Ionics 177(2632):2513-2518

24. Azad S, Marina OA, Wang CM, Saraf L, Shutthanandan V, McCready DE, El-Azab A, Jaffe JE, Engelhard MH, Peden CHF, Thevuthasan S (2005) Appl Phys Lett 86(13): 131906/1-131906/3

25. Kuwata N, Sata N, Tsurui T, Yugami H (2005) Jpn J Appl Phys Part 1 44(12): 8613-8618

26. Lubben D, Modine FA (1996) J Appl Phys 80(9):5150-5157

27. Shin-ichi F, Satoshi S, Kaduhiro S, Hitoshi T (2004) Solid State Ionics 167:325-329

28. Furusawa S, Kawaguchi T (2001) J Phys Soc Jpn 70(12):35853590

29. Fleig J, Rodewald S, Maier J (2000) Solid State Ionics 136137:905-911

30. Park HJ, Kim S (2007) J Phys Chem C 111(40):14903 -14910

31. Atkinson A (1988) Solid State Ionics 28-30(2):1377-1387

32. Jiang S, Wagner JB (1995) J Phys Chem Solids 56(8):1101-1111

33. Knauth P (2000) J Electroceram 5(2):111-125

34. Tuller HL (2000) Solid State Ionics 131(1-2):143-157

35. Mishin Y, Gust W (2001) Ionics 7(4-6):247-263

36. Maier J (2002) Solid State Ionics 148(3-4):367-374

37. Maier J (2003) Solid State Ionics 157(1-4):327-334

38. Harding JH (2003) Interface Sci 11(1):81-90

39. Aleshin AN, Yu V. Aristov, Bokshtein BS, Shvindlerman LS (1978) Phys Status Solid A 45(1):359-366

40. Hwang JCM, Balluffi RW (1978) Scr Metall 12(8):709-714

41. Gust W, Meyer S, Bögel A, Predel B (1985) J Phys Coll C 4 46:537-544
42. Ma Q, Balluffi RW (1993) Acta Metall Mater 41(1):133-141

43. Li XM, Chou YT (1996) Phil Mag A 73(5):1303-1311

44. Sommer J, Herzig Chr, Muschik T, Gust W (1996) Acta Mater 44(1):327-334

45. Surholt T, Molodov DA, Chr. Herzig (1998) Acta mater 46(15):5345-5355

46. Klugkist P, Aleshin AN, Lojkowski W, Shvindlerman LS, Gust W, Mittemeijer EJ (2001) Acta Mater 49(15):2941-2949

47. LeClaire AD (1951) Phil Mag 42:468-474

48. Peterson NL (1983) Diffusion mechanisms in grain boundaries in metals. In: Kedves FJ, Beke DL (eds) Diffusion in metals and alloys. Diffusion and defect monograph series, vol 7. Trans Tech Publications, Schweiz, pp 145-162

49. Sutton AP, Balluffi RW (1995) Interfaces in crystalline materials. Monographs on the Physics and Chemistry of Materials, 51. Clarendon Press, Gloucestershire

50. Herzig Chr, Mishin Y (2005) Diffusion in condensed matter chapter grain boundary diffusion in metals. Springer, Berlin, pp 377-366

51. Murakami M (1980) Thin Solid Films 69(2):253-267

52. Fischer A (1983) Crystal Res Technol 18(11): 1415-1422

53. Luryi S, Suhir E (1986) Appl Phys Lett 49(3):140-142

54. Gilder HM, Chhabildas LC (1971) Phys Rev Lett 26(17):10271030

55. Lanagan MT, Yamamoto JK, Bhalla A, Sankar SG (1989) Mater Lett 7(12):437-440

56. Chen Y, Sellar JR (1996) Solid State Ionics 86-88:207-211

57. Schichtel N, Korte C, Hesse D, Zhakarov N (2009) Structural and Electrical Characterisation of $\mathrm{YSZ} / \mathrm{Sc}_{2} \mathrm{O}_{3}$ and $\mathrm{YSZ} / \mathrm{Lu}_{2} \mathrm{O}_{3} \mathrm{Mul}-$ tilayers on (0001) $\mathrm{Al}_{2} \mathrm{O}_{3}$ Substrates. Thin Solid Films Phys Chem Chem Phys

58. Park ET, Park J-H (1998) Pressure effect on ionic conduction in yttrium-oxide-doped single crystal zirconium oxide. In: Proceedings of the 3rd International Meeting of Pacific Rim Ceramic Societies Kyungju, Korea

59. Kandil HM, Greiner JD, Smith JF (1984) J Am Ceram Soc 67(5):341-346

60. Lee JS, Adams S, Maier J (2000) J Electrochem Soc 147(6):2407-2418 